IX Congresso Brasileiro de Informática na Educação (CBIE 2020)

Anais do XXXI Simpósio Brasileiro de Informática na Educação (SBIE 2020)

\title{
AD-RPG:Elicitando requisitos na idade média utilizando um jogo educacional
}

\author{
Eduardo Luis Lemos ${ }^{1}$, Marcelo Henrique Conceição ${ }^{1}$, Felipe Becker Nunes ${ }^{2}$, Roseclea Duarte \\ Medina $^{1}$, Giliane Bernardi ${ }^{1}$
}

\author{
${ }^{1}$ Universidade Federal de Santa Maria (UFSM) - Santa Maria - RS - Brasil \\ ${ }^{2}$ Antonio Meneghetti Faculdade (AMF) - Restinga Sêca - RS - Brasil \\ \{elemos, hconceicao, rose, giliane\}@inf.ufsm.br, nunesfb@gmail.com
}

\begin{abstract}
The aim of this paper is to present the development of a RPG educational game to support teaching and learning of software requirements elicitation, focusing in two specific techniques: document analysis and interview. The game was built following the ENgAGED development methodology e applied for a group of computer science students. The MEEGA+ model was used to collect and systematize the data. As a result of the player experience attribute, the fun and confidence in learning is evident, highlighted by the totality of students. From the point of view of learning perception, most students pointed the potential of the game for learning the requirements elicitation techniques. So, it is possible to conclude that the AD-RPG game is promising as a complementary tool for teaching and learning requirements elicitation, bringing at the same time an educational and playful activity.
\end{abstract}

Resumo. O objetivo deste artigo é apresentar o desenvolvimento de um jogo educacional, do gênero RPG, para apoiar o ensino e aprendizagem de elicitação de requisitos de software, focando em duas técnicas específicas: análise de documentos $e$ entrevista. $O$ jogo foi construído seguindo a metodologia de desenvolvimento ENgAGED, sendo avaliado por um grupo de estudantes de cursos da área de computação, utilizando o modelo MEEGA+ para coleta e sistematização de dados. Como resultados, pode-se destacar, em relação ao atributo experiência do jogador, a diversão e a confiança na aprendizagem, evidenciada pela totalidade de estudantes respondentes. Do ponto de vista da percepção da aprendizagem, a maioria dos estudantes sinalizou o potencial do jogo para a aprendizagem das técnicas trabalhadas. É possível concluir, a partir da avaliação, que o jogo AD-RPG se apresenta promissor como ferramenta complementar para o ensino e aprendizagem de elicitação de requisitos, trazendo ao mesmo tempo uma atividade educacional e lúdica.

\section{Introdução}

O desenvolvimento de sistemas computacionais exige um conjunto diversificado de conhecimentos da equipe envolvida, nas diferentes fases do projeto. No entanto, mesmo com as evoluções dos últimos anos, os processos de desenvolvimento de software ainda enfrentam desafios, entre eles, segundo Araújo et al. (2016), a dificuldade de dominar as diferentes técnicas, habilidades e conhecimentos necessários. Mais especificamente, cerca de $85 \%$ dos problemas encontrados no desenvolvimento de software originam-se no estágio de elicitação de requisitos (GONÇALVES et al., 2011), estágio no qual há necessidades de desenvolvimento e restrições são identificadas (LUCIA e QUSEF, 2010). O processo de elicitação de requisitos tem um papel crucial no futuro do projeto, sendo que Amaral et al. (2017) ressaltam que uma seleção correta de requisitos deve equilibrar sua importância, orçamento e preferências do cliente. A fim de obter os requisitos dos clientes, os engenheiros 
IX Congresso Brasileiro de Informática na Educação (CBIE 2020)

Anais do XXXI Simpósio Brasileiro de Informática na Educação (SBIE 2020)

de software usam diferentes técnicas de coleta de dados, incluindo entrevistas e análise de documentos, focos da proposta apresentada neste artigo.

Para Brito et al. (2018), atualmente, o papel do profissional da área de computação deixou de ser centrado, especificamente, em suas habilidades técnicas, voltando-se para necessidades associadas à sua habilidade de comunicação, trabalho em equipe e gestão de projetos. No entanto, para os autores, considerando a formação destes profissionais, infelizmente tais competências não conseguem ser exploradas de forma completa no meio acadêmico. Araújo et al. (2016) reforçam estas colocações, inferindo, como causa do déficit de aprendizagem na elicitação de requisitos, estas abordagens consideradas "tradicionais" de ensino. Complementando, Marinato e Alves (2019) destacam que outros autores também discutem esta problemática (BOAS, 2017; BRITO, 2017; SEIXAS et al., 2016), afirmando que as aulas expositivas são um dos fatores de insatisfação e desmotivação nos alunos, que assumem uma posição passiva frente a este tipo de aula, não sendo instigados a ter mais autonomia e independência na busca pelos conhecimentos.

Ao analisar este cenário, torna-se fundamental a diversificação das estratégias educacionais, buscando aproximar o estudante das práticas profissionais, bem como estimulando o mesmo por meio de abordagens mais engajadoras e lúdicas. Dentre as possibilidades, destaca-se neste trabalho o uso de jogos educacionais que, segundo Petri e Chiavegatti (2015), contribuem para manter o foco nas tarefas e colocar em prática o conhecimento do aluno, diante das limitações por práticas em ambientes reais, sem expor ou arriscar qualquer projeto real, porém de forma mais realista e próxima ao futuro profissional dos estudantes. Os jogos têm um grande potencial, pois possibilitam despertar o interesse e manter a motivação do aluno, além de possibilitar o aprendizado de diversos conteúdos em diferentes áreas do conhecimento (ARAÚJO et al. 2016, KALLO e MOHAN, 2016). Diversos gêneros de jogos apresentam diferentes características, entre eles os RPG (RolePlaying Game), que têm como uma de suas características mais fortes a narrativa. Segundo Souza (2015), o RPG proporciona, através do lúdico, um ambiente pelo qual os alunos são atraídos para a classe (neste caso, a atividade). Além disso, jogos de RPG foram recentemente apontados como um exercício frutífero para a Aprendizagem Ativa (MITCHELL et al., 2017), que pode ser descrita como uma atividade instrucional envolvendo o aluno e estimulando o "pensamento" sobre o que eles estão fazendo (BONWELL e EISON, 1991).

Considerando esta perspectiva, buscou-se identificar, por meio de uma Revisão Sistemática de Literatura (RSL), que jogos têm sido desenvolvidos para apoiar o processo de ensino e aprendizagem de elicitação de requisitos, envolvendo exclusivamente o cenário nacional. O resultado desta pesquisa encontra-se publicado em Lemos (2018), sendo que foram identificadas apenas 07 propostas com o foco específico em jogos educacionais voltados à subárea. Nesta mesma direção, Santos et al. (2020) realizaram um mapeamento sistemático, também no cenário nacional, envolvendo jogos educacionais para todas as subáreas da Engenharia de Software, na qual identificaram apenas 3 jogos voltados para Engenharia de Requisitos. Os resultados divergem pelas bases de dados consultadas, no entanto, os 03 jogos encontrados neste mapeamento fazem parte do conjunto dos 07 identificados em Lemos (2018), o que indica a escassez de jogos dedicados à temática.

Com base nos resultados encontrados, considerou-se relevante avançar nas pesquisas, por meio do desenvolvimento de um jogo educacional com tal finalidade. Assim, tem-se o objetivo principal desse artigo, que apresenta o desenvolvimento de um RPG educacional, denominado AD-RPG (Adaptive Role Playing Game), criado para apoiar o ensino e 
IX Congresso Brasileiro de Informática na Educação (CBIE 2020)

Anais do XXXI Simpósio Brasileiro de Informática na Educação (SBIE 2020)

aprendizagem de elicitação de requisitos de software, por meio de atividades educacionais que estimulam o estudante no conhecimento sobre os temas, além de trazer atividades lúdicas, envolvendo a diversão imersa nos processos educacionais.

\section{Trabalhos Relacionados}

Conforme destacado na seção anterior, no início desta pesquisa foi realizada uma RSL, de forma a identificar jogos voltados para o ensino e aprendizagem de elicitação de requisitos (LEMOS, 2018), na qual foram identificados 07 jogos. Entre os trabalhos analisados para este trabalho pode-se citar o SE * RPG, apresentado por Benitti e Jefferson (2008), um RPG para o ensino de Engenharia de Software que usa gráficos 3D, imergindo o jogador em uma empresa de desenvolvimento de software. A partir dos resultados obtidos, os autores enfatizam que o $\mathrm{SE} * \mathrm{RPG}$ pode minimizar a lacuna entre aprendizado teórico e prático.

Outro exemplo encontrado é o trabalho de Thiry et al. (2010), que apresenta o jogo Ilha de Requisitos como ferramenta de ensino de Engenharia de Requisitos, em que o jogador deve utilizar o conhecimento sobre a elicitação de requisitos para cumprir as missões e escapar da ilha onde está preso. O jogo tem gráficos 2D mostrando apenas imagens interativas com poucas animações para o jogador, concentrando-se em ensinar de forma aliada à diversão, e focando na narrativa da história apresentada.

Por fim, destaca-se o trabalho de Petri e Chiavegatti (2015), que apresenta um RPG chamado EAReq-GAME, que coloca o jogador no papel de um engenheiro de requisitos responsável por coletar e analisar os requisitos nos cenários simulados, utilizando a técnica de análise de cenários. Este jogo também usa gráficos 2D, permitindo movimentos baseados em cenários, inserindo o jogador em um ambiente simulando um local real.

O jogo proposto e apresentado neste artigo difere dos anteriores por utilizar gráficos 3D, além de buscar inserir o jogador em um mundo lúdico, onde as atividades de elicitação de requisitos são apresentadas ao jogador de forma integrada com os desafios e missões da história, através de objetos educacionais inseridos na narrativa, além de disponibilizar conteúdos educacionais para auxiliar o aluno durante as atividades. Por fim, o jogo acrescenta um sistema de adaptação ao estilo de aprendizagem para melhor apresentar o material didático ao aluno, que não será foco deste artigo.

\section{Aspectos Metodológicos}

Inicialmente, foi realizada uma revisão bibliográfica para encontrar uma metodologia de desenvolvimento adequada para a criação de jogos educativos. A partir disso, foi escolhida a metodologia para desenvolvimento de jogos educacionais ENgAGED (Educational Games Development), proposta por Battistella e Wangenheim (2015). Como ferramenta de desenvolvimento foi escolhida a Unity3D e, como banco de dados, o MySQL.

Considerando a arquitetura do jogo (Figura 1), o jogador interage com a interface 3D usando o teclado e o mouse. Em um nível inferior à interface, tem-se três estruturas principais de controle: Gerenciador de Missões, responsável por controlar os pré-requisitos para iniciar e concluir uma atividade e as recompensas; Monitoramento de Desempenho, que monitora o jogador em relação às suas interações dentro do sistema de aprendizagem, sendo responsável por identificar e salvar as novas informações no banco de dados; e o módulo Sistema de Aprendizagem, que tem o objetivo de gerenciar os conteúdos educacionais, definindo qual 
material de apoio deve ser apresentado ao aluno, de acordo com uma estratégia de adaptação automática que considera o estilo de aprendizagem do estudante, bem como a trajetória dele no jogo e a missão atual.

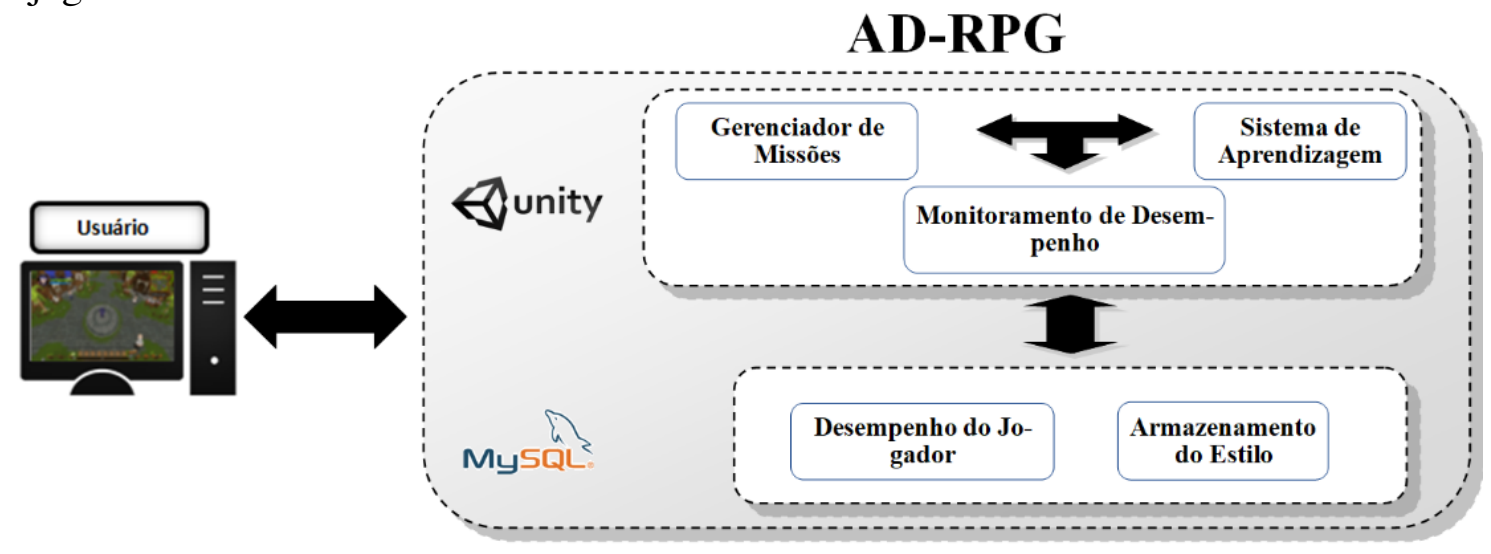

Figura 1. Arquitetura do jogo (Fonte: do autor)

Por fim, tem-se o banco de dados, que foi projetado para armazenar dados sobre o desempenho do jogador, tais como tempo de conclusão do jogo, missões concluídas e pontuação (Desempenho do Jogador), assim como armazenar dados sobre seus estilos de aprendizagem, para adaptação (Armazenamento de Estilo). Com relação aos conteúdos educacionais, conforme mencionado anteriormente, o jogo abrange questões relacionadas à elicitação de requisitos de software, enfatizando o uso de duas técnicas para coleta de dados, a entrevista e a análise de documentos. Neste contexto, uma entrevista pode ser descrita, de acordo com o Guia BABOK (Corpo de Conhecimento da Análise de Negócios), como uma abordagem sistemática para obter informações de uma pessoa ou grupo, sendo possível ser formal ou informal (BABOK, 2015). A análise de documentos, por sua vez, consiste na visualização e análise de documentos e é geralmente utilizada quando o objetivo é coletar detalhes de soluções existentes (informatizadas ou não), por meio de sua documentação (BABOK, 2015).

Para a avaliação do jogo desenvolvido foi utilizado o modelo MEEGA+, desenvolvido para avaliar jogos educacionais por meio de um questionário padronizado, aplicado após o uso do jogo, avaliando duas categorias: experiência do usuário e percepção da aprendizagem (PETRI e VON WANGENHEIM, 2017).

\section{Apresentação do Jogo AD-RPG}

O jogo proposto foi denominado AD-RPG - Adaptive Role Playing Game, considerando que tem como objetivo principal a adaptação dos conteúdos educacionais de apoio, de acordo com o estilo de aprendizagem do aluno durante o jogo, permitindo a disponibilização dinâmica de conteúdos educacionais adaptados. Ressalta-se que este artigo está centrado em discutir apenas os aspectos relacionados ao desenvolvimento do jogo e suas missões do ponto de vista do ensino de elicitação de requisitos, não enfocando as questões relacionadas à adaptação de estilos de aprendizagem, que podem ser encontradas em Lemos (2018).

Para a construção do jogo, foi elaborada a seguinte narrativa: o jogador (estudante) deve assumir o papel de um estudioso que volta no tempo para a Idade Média, cuja missão é obter detalhes sobre as atividades profissionais da época. Para coletar estes dados, é necessário conhecer as técnicas de elicitação de requisitos, que serão passadas a ele por meio 
dos materiais educacionais presentes no jogo. O jogo começa sua narrativa com uma introdução, contextualizando o jogador na história e justificando os eventos que se seguirão, sendo conduzido, após, a uma fase-tutorial, na qual são apresentados os conteúdos educacionais sobre o uso da interface e características do ambiente. O jogador pode escolher ler ou ignorar o que está sendo apresentado a ele, seguindo este modelo de interação ao longo de todo o jogo. Depois que o jogador completa esta fase de apresentação, ele é transportado para a vila central da história, na qual sua principal aventura começa (Figura 2).

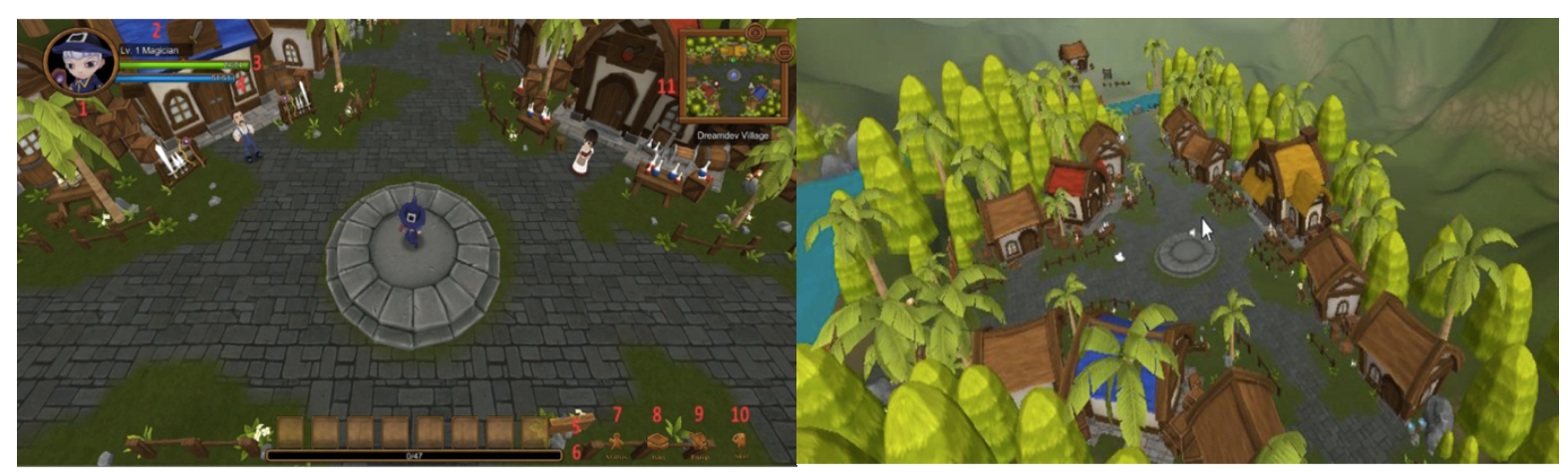

Figura 2 - Interfaces do Jogo AD-RPG - à esquerda, interface do jogo; à direita, visão geral da vila - (Fonte: do autor)

Para obter a primeira missão, o jogador deve falar com a NPC (Non-Player Character) denominada Ana Braga, cozinheira chefe da aldeia, que passa ao jogador a tarefa de explorar a floresta em busca do seu melhor cozinheiro que desapareceu enquanto buscava ingredientes para uma ocasião festiva, na qual deveriam cozinhar uma receita especial para o rei, sendo que apenas este cozinheiro sabe prepará-la. No entanto, o jogador encontra apenas o diário do cozinheiro, que deve ser devolvido a cozinheira. Após uma breve conversa com Ana Braga, o jogador recebe uma nova tarefa: ler o livro e identificar as informações necessárias para a preparação da receita secreta (Figura 3).

Esta missão, do ponto de vista de Engenharia de Software, envolve elencar requisitos funcionais e não funcionais que, neste caso, estão ludicamente imersos na forma de ingredientes necessários para a receita (essenciais e complementares), modo de preparo (funcionalidades), bem como particularidades que podem melhorar a qualidade da receita. A técnica de elicitação adotada nesta missão é a análise de documentos, sendo o Diário do Cozinheiro o documento em questão. Como apoio à esta missão, o estudante tem a disposição recursos educacionais relacionados aos conteúdos que envolvem a missão, como a definição e exemplificação de requisitos funcionais e não-funcionais, bem como diretrizes para condução de uma análise de documentos.

Após completar o primeiro objetivo, o aluno recebe acesso à segunda missão do jogo, que visa abordar a técnica de entrevista para elicitação de requisitos (Figura 4). Nesta atividade, o jogador interage com o jovem ferreiro da aldeia, que pede sua ajuda para aprender o processo de fabricação de uma espada. Ao término do diálogo, o jogador deve procurar o ferreiro aposentado que detém o conhecimento sobre este processo, para, através da técnica de entrevista, compreender como fabricar uma espada do tipo Katana, no que concerne a requisitos funcionais (neste caso, os insumos essenciais para produzir a lâmina e o punho) e não funcionais (materiais e atividades adicionais que podem melhorar a qualidade da lâmina e o punho). A missão foi pensada tomando como referência o processo de entrevista descrito em Babok (2015) e Carvalho e Chiossi (2001), que identificam 03 fases deste processo: planejamento, execução da entrevista e registro dos resultados obtidos. 


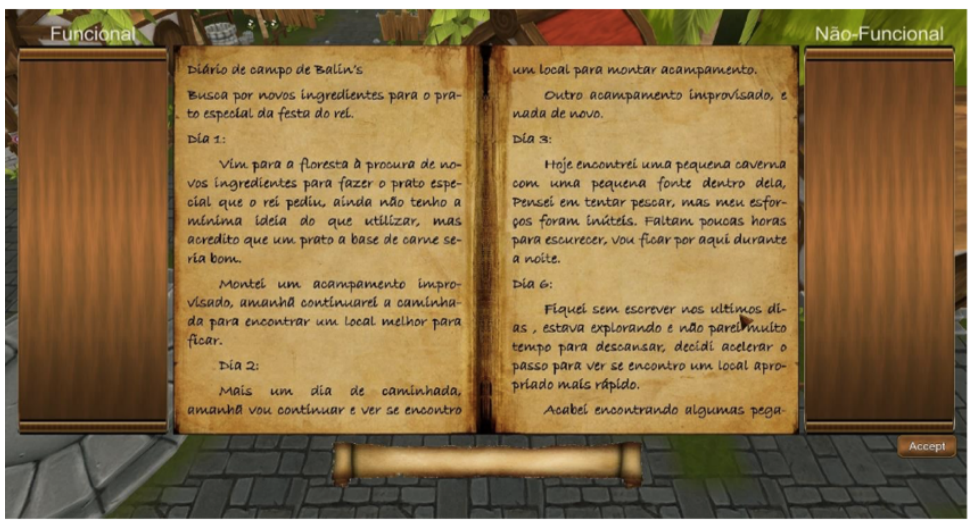

Figura 3 - Primeira Missão - Análise de Documentos (Fonte: do autor)

Neste caso, o primeiro passo deve ser o planejamento da entrevista, no qual o jogador escolhe, quais perguntas deseja aplicar durante a entrevista. Do ponto de vista de Engenharia de Software, esta pode ser considerada uma entrevista formal e estruturada, na qual as perguntas são planejadas com antecedência. Por limitações de implementação optou-se por um conjunto limitado e fechado de questões. No entanto, cabe ao estudante selecionar as questões que considera relevantes e importantes no contexto desta entrevista, bem como a ordem em que ele deseja aplicá-las, pensando em diretrizes para condução de uma boa entrevista (CARVALHO e CHIOSSI, 2001). Ressalta-se, novamente, que os materiais de apoio sobre a técnica, envolvendo conceitos e diretrizes para realização, estão disponíveis ao estudante, que pode visualizar os mesmos quando desejar.
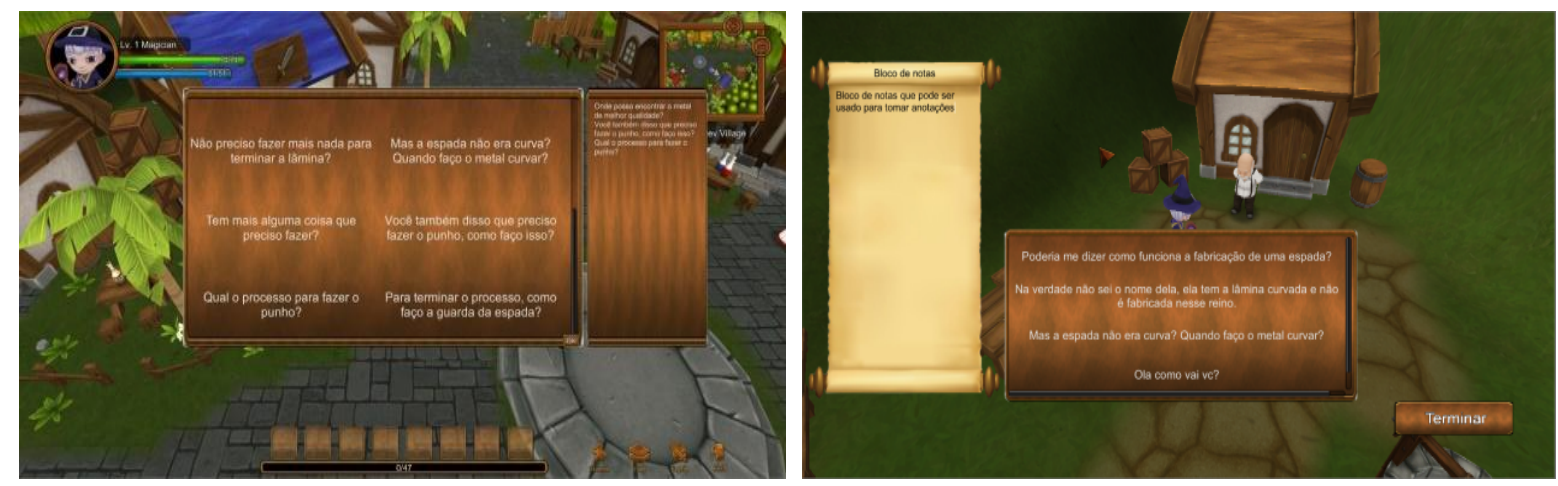

Figura 4. Segunda Missão - Planejamento e Execução de Entrevista (Fonte: do autor).

O segundo momento desta missão é a execução da entrevista, na qual o jogador faz as perguntas, planejadas previamente, para o ferreiro aposentado, dispondo de um bloco de notas para anotações (localizado ao lado esquerdo da tela). A partir deste, o jogador pode fazer anotações relacionadas às respostas obtidas, para que no final possa identificar corretamente os requisitos, chegando por fim na terceira fase da entrevista, na qual revisa suas anotações, formaliza/registra suas conclusões e submete para avaliação. Neste caso, a submissão envolve repassar os requisitos coletados para o jovem ferreiro, para que este possa construir a espada desejada. Destaca-se que em todas as missões o sistema executa um processo automatizado de correção, para dar seguimento à narrativa, bem como trazer feedback ao estudante.

Após completar cada um dos objetivos, uma missão lúdica é desbloqueada, sendo que tais missões foram pensadas com o objetivo de integrar diversão à aprendizagem, buscando 
IX Congresso Brasileiro de Informática na Educação (CBIE 2020)

Anais do XXXI Simpósio Brasileiro de Informática na Educação (SBIE 2020)

uma maior experiência do estudante com o jogo. Ressalta-se que ambas as missões lúdicas não são obrigatórias para a conclusão do jogo.

\section{Avaliação e Discussão dos Resultados}

A avaliação do jogo consistiu na aplicação do mesmo, a fim de obter as percepções de alunos sobre o jogo em si (do ponto de vista de experiência de uso), bem como seu potencial em auxiliar na aprendizagem de técnicas de elicitação de requisitos. Participaram desta avaliação dez alunos de cursos de graduação da área de computação. Petri e Von Wangenheim (2017) salientam que vários jogos não cumprem a sua missão de entreter os alunos, pois desconsideram a jogabilidade e concentram-se apenas no conteúdo a ser ensinado. Através da aplicação do MEEGA+, dois atributos centrais foram avaliados quantitativamente: a Experiência do jogador, que se subdivide em Usabilidade, Confiança, Desafio, Satisfação, Diversão e Atenção Focada; e a Percepção da Aprendizagem, que é composta por perguntas focadas na aprendizagem do conteúdo abordado, neste caso, sobre elicitação de requisitos.

Um ponto que se destacou positivamente foi a Usabilidade, mantendo a mediana positiva na maioria das questões avaliadas, sendo que a mesma varia de -2 a 2 . No entanto, quando se trata de proteção contra erros e recuperação de erros, ou seja, quando ocorre um evento inesperado (o jogo falha, o banco de dados falha, o avatar fica preso) e o jogador é forçado a reiniciar, as respostas dos jogadores foram negativas, demonstrando a necessidade de melhorias nesses aspectos.

No quesito Confiança, buscava-se obter a impressão dos estudantes com relação ao potencial do jogo para que fizessem progresso no estudo dos conteúdos educacionais, sendo que $100 \%$ dos estudantes (concordaram totalmente - CT ou concordaram parcialmente - CP) sinalizaram estar confiantes de que aprenderiam com o AD-RPG. Com relação às missões e dificuldades impostas aos desafios, os estudantes responderam positivamente à variedade de desafios, afirmando que o jogo não se torna monótono nas suas tarefas $(88,5 \%)$. No entanto, apenas 34\% dos estudantes acharam o jogo adequadamente desafiador (CT e CP), tendo 44\% mantendo-se neutros e $22 \%$ discordando parcialmente. Isso pode ter ocorrido ao considerarmos que as missões do jogo envolviam apenas conceitos básicos e fundamentais de elicitação de requisitos, não explorando aspectos mais avançados do conteúdo. No quesito Satisfação, 91,5\% dos estudantes manifestaram-se concordando total ou parcialmente $(8,5 \%$ mantiveram-se neutros), em questões que indagavam sobre o grau com que se sentiram realizados utilizando o jogo e se o indicariam a colegas.

No quesito Diversão, 100\% dos estudantes manifestaram-se positivamente (56\% CT e 44\% CP), evidenciando que a busca pela união de aspectos educacionais e lúdicos foram percebidos de forma positiva. Com relação à Atenção Focada, na média das questões, 85\% (CT e CP) dos estudantes consideraram que o jogo os manteve envolvidos e imersos na atividade, fazendo com que esquecessem do ambiente ao redor.

Passando para a avaliação da Percepção da Aprendizagem, sob o ponto de vista dos estudantes, em geral, as respostas obtidas indicam que o jogo pode auxiliar neste processo. Quando perguntados se o jogo contribuiu para aprendizagem do tema, 90\% das respostas foram positivas e $10 \%$ se mostraram indiferentes. Além disso, $70 \%$ dos alunos responderam que o jogo contribuiu para o aprendizado, em comparação com outras atividades da disciplina, $10 \%$ foram indiferentes e $20 \%$ foram respostas negativas. Esses resultados demonstram que o jogo foi bem avaliado como ferramenta complementar de aprendizagem, 
mostrando seu potencial de uso. Ao abordar a aprendizagem dos conteúdos individuais, $100 \%$ dos alunos responderam que o jogo pode contribuir para o aprendizado sobre a Análise de Documentos, requisitos funcionais e não funcionais; e $80 \%$ consideraram que o jogo contribuiu para o aprendizado da técnica de Entrevista, sendo que 20\% demonstraram-se indiferentes. Quando perguntados se, em geral, o jogo contribuiu para o aprendizado, 80\% das respostas foram positivas, $10 \%$ ficaram indiferentes e $10 \%$ foram respostas negativas. A partir desses resultados é possível inferir que os conteúdos foram bem abordados durante o andamento do jogo, e contribuíram para o aprendizado do aluno. Estes valores são indicativos do potencial de aprendizagem do jogo.

Por fim, os alunos foram solicitados a descrever os pontos fortes do jogo, sugestões de melhorias e, se desejado, quaisquer comentários adicionais. Os tópicos mais citados quando questionados sobre os pontos fortes do jogo foram relacionados à interface, gráficos, aparência e design, demonstrando que o design do jogo pode ser considerado um destaque, não necessitando alterações, apenas pequenas correções. Nas sugestões de feedback de melhoria, surgiram algumas sugestões relacionadas às fontes do texto, adição de um menu de configuração dentro do jogo, bem como de pequenas indicações ou dicas para auxiliar o jogador, entre outros.

O jogo foi projetado para ser aplicado em dois períodos de aula de 50 minutos, sendo considerado neste tempo total o momento inicial de preparação para a execução. O tempo utilizado pelos participantes variou de 43 a 88 minutos, com tempo médio de conclusão do jogo de 69 minutos. A partir desses resultados, conclui-se que o jogo atingiu o tempo planejado para sua execução completa. Como pontos positivos obtidos através das observações dos alunos, é possível citar o engajamento com o jogo, um termo definido por Fredricks e Silveira (2016) como estar envolvido em alguma coisa, comprometido em fazer algo com dedicação e determinação. No contexto educacional, engajamento pode ser considerado o comprometimento do aluno em sua vida acadêmica (FREDERIKS et. al., 2004). Em muitos momentos, o pesquisador observou risos, jogadores "pensando" em voz alta e discutindo consigo mesmo as atividades.

Outro fato observado é que dos dez voluntários, oito completaram pelo menos uma missão lúdica e fizeram comentários positivos sobre elas em suas avaliações, o que evidencia o exposto por Vieira e Mezzaroba (2010), quando afirmam que o aspecto lúdico pode favorecer a adaptação do paradigma da educação tradicional a uma educação construtiva, dinâmica e divertida. Além disso, Rocha et al. (2013) indicam que ao utilizar metodologias lúdicas para compartilhar conhecimentos, a aprendizagem é facilitada, pois requer atividades práticas e diferenciadas do aluno.

Entre os pontos negativos observados, há casos de alunos perdidos durante as tarefas, indicando a necessidade de mais sinais de orientação presentes ao longo do jogo. Além disso, pequenos erros de jogabilidade foram encontrados, como a possibilidade de andar para fora do mundo em um ponto específico. Além disso, percebeu-se a necessidade de melhoria na indicação das localidades do jogo (aldeia e floresta) com placas.

\section{Considerações Finais}

Este artigo apresentou o desenvolvimento de um jogo de RPG para apoiar o ensino e aprendizagem de elicitação de requisitos de software, trazendo uma atividade complementar ao ensino usualmente expositivo, criando um ambiente no qual os alunos podem se envolver 
em atividades experimentais e lúdicas relacionadas às técnicas de análise de documentos e entrevista.

Por meio dos resultados obtidos, foi possível observar que o jogo se apresenta promissor como estratégia educacional. Seguindo o feedback obtido pelos estudantes que realizaram a avaliação, o jogo contribuiu para o aprendizado dos conteúdos propostos, trazendo indícios de que tem potencial real para seu uso. No entanto, embora esses resultados tenham sido positivos, a avaliação também apontou melhorias necessárias, que devem ser revistas e modificadas para expandir este projeto. Ainda, em trabalhos futuros, outras sugestões oferecidas pelos alunos foram a ampliação do jogo, agregando mais missões (didáticas e lúdicas) e expansão do ambiente, bem como da história, trazendo novos NPC. Atualmente, o professor precisa acessar o banco de dados para verificar o desempenho do aluno. Está prevista uma modificação no jogo, permitindo a leitura dos dados através de uma interface web que facilite a visualização das informações, implementando filtros, gráficos e outras ferramentas que auxiliem o professor na análise do desempenho dos jogadores.

Por fim, embora os resultados tenham sido indicativos do potencial do jogo, uma avaliação mais detalhada ainda é necessária para trazer mais resultados e dados de análise, com um número mais significativo de alunos e sua inclusão nas aulas de Engenharia de Software, buscando novas estratégias de avaliação, como validação através de testes estatísticos.

\section{Referências}

Amaral, A. and Elias, G. (2017) "A Risk-Based Approach for Selection Software Requirements”. Anais do Simpósio Brasileiro de Sistemas de Informação. Lavras, MG.

Araújo, D. N., Cruz, M. L. P., Pimentel, J. H., Duque, M.; Alencar, F. (2016) "Jogos Educativos no Ensino da Engenharia de Requisitos”. Anais do IX FEES. Maringá, PR.

Araújo, D. C., Rodrigues, A. N., Lima, P. V. de L., Ferreira, M. A. D., Santos, H. R. M. (2016) "Processo de Desenvolvimento do jogo sério Missão Aedes: relações entre objetivos pedagógicos, ludicidade e implicações de design”. Anais do XXVII Simpósio Brasileiro de Informática na Educação (SBIE). Uberlândia, MG.

Barboza A. T. and Silveira I. F. (2016) "PerMotivE: Um modelo conceitual para Persuasão, Motivação e Engajamento para jogos Educacionais". In: XV Simpósio Brasileiro de Jogos Digitais e Entretenimento (SBGAMES), São Paulo, SP.

Battistella P. E. and Wangenheim C. G., (2015) ENgAGED: Processo de Desenvolvimento de Jogos para Ensino em Computação”. Relatório técnico, INCoD - UFSC

Benitti, F. B. V. and Jefferson, S. M. (2008) "Utilização de um RPG no Ensino de Gerenciamento e Processo de Desenvolvimento de Software". In: XXVIII WEIWorkshop sobre Educação em Computação.

Boas, J. L. V., Teixeira, M. A. L., Damaceno, E. F., Brancher, J. D. (2017) “GamAPI-Uma API para Gamificação". Informática na educação: teoria \& prática, v. 20 n.1.

Bonwell C. C. and Eison J. A. (1991) "Active learning: Creating excitement in the classroom". Washington, DC: Association for the Study of Higher Education.

Brito, L. F., Ramos, R. A., de Oliveira Neto, R. F., Leal, B. G. (2018) “Avaliação Do Jogo SIMULES No Apoio Ao Ensino e Aprendizagem de Engenharia de Software". Brazilian Journal of Education, Technology and Society (BRAJETS). 
Brito, A. L. de S. (2017) "Level Up: uma proposta de processo gamificado para a educação". Dissertação (Mestrado) - Mestrado Profissional em Engenharia de Software, PPG em Engenharia de Software, Universidade Federal do Rio Grande do Norte, Natal.

Carvalho, A. M. R. and CHIOSSI, T. C. S. (2001) "Introdução à Engenharia de Software". Campinas: Editora da Unicamp.

Fredricks J. A., Blumenfeld P. C., Paris A. H. (2004) "School engagement: Potential of the concept, state of the evidence". Review of Educational Research.

BABOK (2015) "Um guia para o Corpo de Conhecimento de Análise de Negócios BABOK GUIA v.3.0.”. IIBA.

Gonçalvez, R. Q., Thiry, M., Zoucas, A. (2011) “Avaliação da aprendizagem em experimentos com jogos educativos de engenharia de requisitos". Anais do X Simpósio Brasileiro de Qualidade de Software (SBQS), Curitiba.

Kalloo, V. and Mohan, P. (2016) "An Investigative Process for Enhancing the Design of a Mathematics Learning Game". In: 16th ICALT. IEEE.

Lemos, E. L. (2018) “AD-RPG: Elicitando requisitos na idade média por meio de um jogo educacional adaptativo”. Dissertação de Mestrado em Ciência da Computação, PPGCC da Universidade Federal de Santa Maria.

Lucia A. and Qusef A. (2010) "Requirements Engineering in Agile Software Development". Journal of Emerging Technologies in Web Intelligence.

Marinato, M. S. and Alves, S. V. L (2019) "Uma proposta de gamificação para o ensino da Engenharia de Software". In: Anais dos Workshops do Congresso Brasileiro de Informática na Educação. Brasília, DF.

Mitchell A., Petter S., Harris A. L. (2017) "Learning by Doing: Twenty Successful Active Learning Exercises for Information System Courses”. Journal of Information Technology Education: Innovations in Practice.

Petri G., Von Wangenheim C. G., Borgatto A. F. (2017) "Evolução de um Modelo de Avaliação de Jogos para o Ensino de Computação". XXV CSBC/WEI. São Paulo, SP.

Petri, G. and Chiavegatti, N. C. (2015) "Um role playing game para o ensino de elicitação e análise de requisitos". Revista Novas Tecnologias na Educação. v. 13, n. 1.

Rocha J.F. S., Onezino G. M., Kenia K., Gomes W. F. (2013) "Em jogo os Direitos e Deveres dos Servidores Públicos do Estado de Sergipe”. In: Anais do XXIV Simpósio Brasileiro de Informática na Educação (SBIE). Campinas, SP.

Santos, S. H. N., Costa, Y. D. J. S., dos Santos, D. V., Barradas Filho, A. O., Junior, J. B. B., Cabrejos, L. J.E. R. (2020) Identifying Serious Games for Software Engineering Teaching in Brazil Through a Systematic Mapping Study. Research, Society and Development.

Seixas, L. da R., Gomes, A. S., Melo Filho, I. J. (2016) "Effectiveness of gamification in the engagement of students". Computers in Human Behavior.

Souza, E. S. (2015). "Uso de jogos de role playing game (rpg) como uma estratégia possível de aprendizagem de conteúdos de biologia na educação de jovens e adultos". Revista Cientifica Interdisciplinar.

Thiry M., Zoucas, A., Gonçalves, R. Q. (2010) "Promovendo a Aprendizagem de Engenharia de Requisitos de Software Através de um Jogo Educativo”. In: XXI SBIE, João Pessoa, PB.

Vieira C. and Mezzaroba C. (2010) “Ludoeducação.” IADE Publicações, Blumenau, SC. 